\title{
Análisis de elementos gráficos de contenido occidental en los glifos de los códices coloniales del centro de México: el caso de los antropónimos castellanos
}

\author{
Juan José Batalla Rosado \\ Universidad Complutense de Madrid \\ batalla@ghis.ucm.es
}

Recibido: 20 de octubre de 2014

Aceptado: 15 de noviembre de 2014

\section{RESUMEN}

En este trabajo presentamos el estudio de los glifos nahuas coloniales de antropónimos castellanos que contienen algún elemento occidental en su composición. Es decir, analizamos los «prestamos» que los tlacuiloque o escribas indígenas tomaron para escribirlos. Para llevarlo a cabo hemos revisado multitud de códices aunque somos conscientes de que no hemos tenido acceso a todos ellos. No obstante, consideramos que el resultado final recoge la mayor parte de ellos y ofrece datos que nos permitirá en próximos estudios relacionar antropónimos nahuas, topónimos, oficios, cargos, barrios, etc., en los que también se incluyeron elementos culturales occidentales.

Palabras clave: Códices mesoamericanos, escritura jeroglífica náhuatl, cultura azteca.

\section{Analysis of Western Graphics Elements in the Glyphs of Colonial Central Mexican Codices: The Case of Spanish Anthroponyms}

\begin{abstract}
In this text, we present the study of Spanish anthroponyms containing «Western» elements. We analyze the «loans» that the tlacuiloque or indigenous scribes borrowed in order to express these names in a traditional graphic form. We have examined many codices, but we are aware that we have not had access to all of them. However, we believe that the final results of this research are based on the representative sample encompassing the majority of extant sources, thus providing information that will make it possible to establish in future studies relationships between Nahua anthroponyms, place names, offices, functions, barrios..., in which also embrace Western cultural elements.
\end{abstract}

Key words: Mesoamerican codices, Nahuatl hieroglyphic writing, Aztec culture.

Sumario: 1. Introducción. 2. Antropónimos occidentales. 3. Antropónimos no descifrados. 4. Conclusiones. 5. Referencias bibliográficas.

\section{Introducción}

Para llevar a cabo este trabajo, relativo al estudio de elementos gráficos occidentales en los glifos de los códices del centro de México, hemos procedido a analizar todos aquellos documentos pictográficos mesoamericanos coloniales ${ }^{1}$ a los que hemos tenido acceso a través de sus publicaciones en sus diversos soportes, incluyendo los disponibles a través de internet. Somos conscientes de que no hemos podido revisar su totalidad puesto que algunos de ellos siguen sin estar editados, salvo por su visionado directo en la institución que los resguarda. No obstante, afirmamos que hemos

${ }^{1}$ Los datos conocidos sobre los mismos, ediciones y bibliografía pueden ser consultados en la página web de wiki filología (www.iifl.unam.mx/wikfil). 
accedido a su mayor parte, con lo cual consideramos que el análisis realizado ha cubierto casi el total de los mismos.

Por otro lado, por razones de espacio, nos hemos centrado exclusivamente en el análisis de los glifos de antropónimos o nombres de persona castellanos, entendiendo que consideramos tanto lo que denominamos nombre propio como apellido, puesto que incluir, por ejemplo, nombres de los santos de la Iglesia Católica, topónimos, barrios, cargos y oficios, superaba con creces este artículo ${ }^{2}$. Por ello, nos ocupamos exclusivamente de glifos conformados por elementos occidentales, dado que la aculturación producida entre los escribas indígenas llevó a que adoptaran algunos de ellos para expresar los nombres. En ningún caso incluiremos antropónimos occidentales cuyo glifo esté conformado mediante representaciones culturales indígenas ${ }^{3}$.

De igual modo, hemos decidido no considerar aquellos elementos jeroglíficos que, pese a estar influenciados por lo occidental y representados incluso conforme a nuestra cultura, ya eran utilizados en la escritura e iconografía prehispánica, como el sol, la luna, las estrellas, los ojos, construcciones, etc. Es decir, deseamos dejar claro que sólo incluiremos elementos que no existían en el mundo prehispánico y que por lo tanto supusieron un «préstamo» y no aquellos ya existentes cuyo diseño se occidentalizó.

Además, debemos reseñar que el pionero en el análisis de estos nombres occidentales fue Joaquín Galarza ${ }^{4}$ quien, desde su primer artículo sobre este tema, hasta el libro en el que recopiló todos los publicados referentes al mismo (Galarza 1962 y 1980, respectivamente), estudió los plasmados en los códices Alfareros de Cuauhtitlan, Aubin o de 1576, Mexicanus 23-24, Osuna, Proceso de Cuauhtitlan, Plano de las casas de Juan de Xalbornoz, San Andrés, Santa Anita Zacatlalmanco, etc. Por ello, no nos parece adecuado repetir aquí los glifos que él examinó y cuando tengamos que hacer referencia a ellos, remitiremos en primer lugar a los analizados en sus estudios ${ }^{5}$.

Por último, hemos tenido que incluir un apartado de «antropónimos no descifrados», tanto por no coincidir lo escrito en la glosa y el glifo, como por no ser posible interpretar algunas de las dos formas de plasmación e incluso por la ausencia de glosa. Todos ellos serán presentados por orden alfabético.

\section{Antropónimos occidentales}

ANDRÉS (Figura 1). Para la confección de su glifo los tlacuiloque recurrieron a la iconografía cristiana de San Andrés apóstol: la cruz en aspa o cruz decussata en

2 Los antropónimos nahuas que contienen elementos occidentales en la composición de sus glifos serán presentados en otro trabajo (Batalla, en prensa). Así mismo, los nombres de los santos, topónimos, barrios, oficios, etc., que contengan algún elemento occidental también serán objeto de otros estudios, pues los apelativos de los santos en muchas ocasiones aparecen como topónimos (localidades y barrios).

3 Uno de los ejemplos más clásicos es el de Francisco (Galarza 1980: 59 y lámina 3.6), si bien, como veremos, tendremos que incluir en este estudio uno de sus glifos (véase Figura 8).

4 Aunque somos muy críticos con el «método» de estudio de los códices creado por este investigador siempre hemos reconocido la validez de su investigación en este tema concreto de los glifos de nombres castellanos (véase Batalla 2008: 59).

5 Tampoco incluiremos los nombres ya estudiados por J. Galarza (1980: 54-57) de los que no hemos hallado ejemplos en otros códices a los que él no accedió, como por ejemplo Agustín, Bartolomé, Catalina, María, Timoteo, etc. 
Figura 1: Glifo de Andrés: a) Códice de los tributos de San Pablo Teocaltitlan (s/f: f. 5r);

b) Mapa Beinecke (Whittaker 2012: 189).
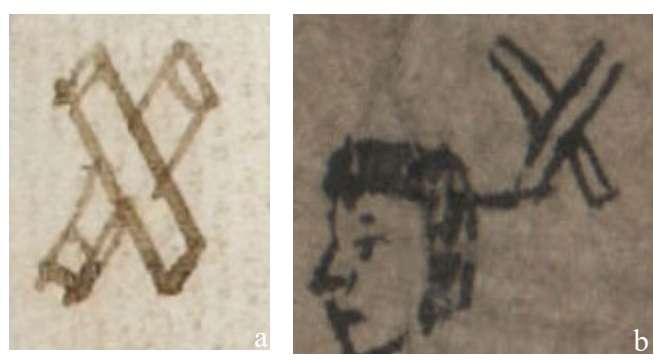

Figura 2: Glifo de Camisa en la Matrícula de Huexotzinco (Prem 1974): a) camissa (fol. 498r); b) camisa (fol. 713r); c) camisa (fol. $725 \mathrm{r}$ ); d) mocamissamaca (fol. $693 \mathrm{v})$; e) tlapalcamissa (fol. 779v).
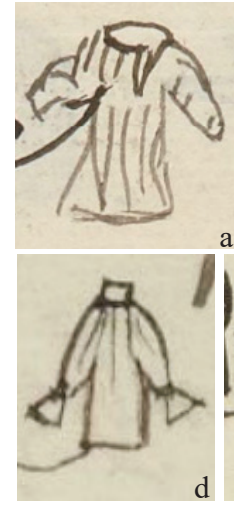
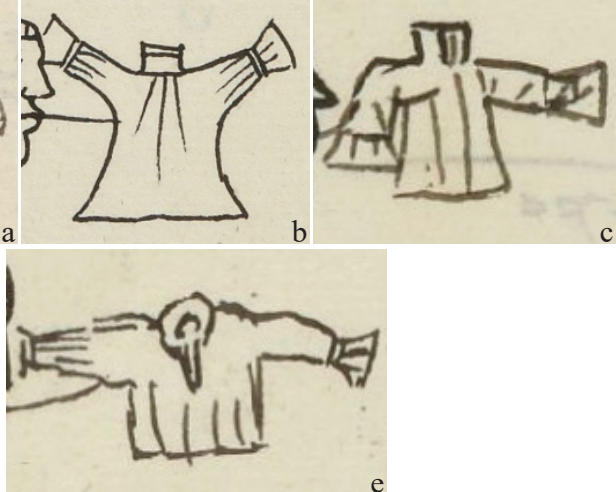

la que fue martirizado (Réau 2000: 89). Así aparece en el Códice de los Alfareros de Cuauhtitlan (Galarza 1980: 79, lám. 3.8, $\mathrm{n}^{\mathrm{o}}$ 3), en los folios 5r y 14r del Libro de los tributos de San Pablo Teocaltitlan ${ }^{6}$ (s/f) (Figura 1a) y en el Mapa Beinecke (Whittaker 2012: 189) (Figura 1b).

CAMISA (Figura 2). El apellido Camisa (Prem 1974: 547) aparece en cinco ocasiones en la Matrícula de Huexotzinco $(\mathrm{s} / \mathrm{f})^{7}$ con un glifo que representa esta prenda de vestir castellana. Las glosas que lo acompañan leen «camisa» en tres de los nombres (folios 498r, 713r y 725r; Figuras 2a, 2b y 2c), pero en el folio 693v el término es mocamissamaca y en el 779v tlapalcamisa. El primero de ellos (Figura 2d) se compone del prefijo mo-, la camisa y el verbo maca- «dar algo a otro, o restituir» (GDN 2012) ${ }^{8}$,

6 Respecto de este códice, conservado en la Biblioteca Nacional de Francia (BNP mex 376), hemos de tener presente que, en nuestra opinión, la mayor parte de los antropónimos de las mujeres (todas viudas) que aparecen en forma de glifo y escritura alfabética nunca coinciden, salvo contadas ocasiones, pues el glifo indica el nombre del marido fallecido y la glosa el de la mujer. Por otro lado, hemos de indicar que, aunque J. Galarza (1980) no lo utilizó en sus estudios, H.J. Prem ya lo hizo en un trabajo anterior, si bien lo nombra erróneamente BNP mex 276 (Prem 1970: 164), pero sólo incluye un diseño a línea de Pedro, Juan, Andrés y Gregorio (Prem 1970: 164, figuras 4a-4c-4d-4e), y serán tratados aquí junto con otros que no analizó.

7 Hasta que la Biblioteca Nacional de Francia lo incluyó en su página web, sólo disponíamos de una edición en blanco y negro (Prem 1974), que sigue siendo imprescindible para su análisis, pues contiene un amplio estudio, la paleografía de muchas de sus páginas y el glosario de términos recogidos en las glosas de sus miles de glifos (Prem 1974: 531-700).

8 El Gran Diccionario Nahuatl, publicado en línea por la UNAM (México), constituye una herramienta imprescindible para el estudio de esta lengua (incluye varios diccionarios de los siglos XVI al XXI), debiendo unir al mismo el Nahuatl Dictionary (s/f) de la Universidad de Oregon, también excepcional por incluir citas etnohistóricas donde aparecen los términos nahuas. Así mismo, hemos consultado el programa Tlachia (www. 

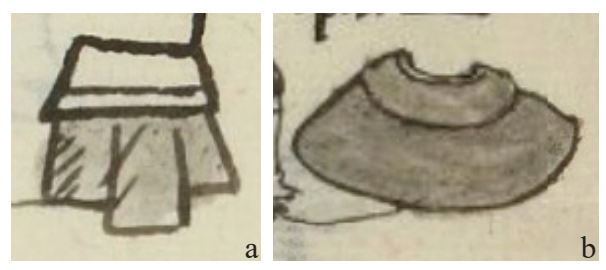

Figura 3: Glifo de Capa en la Matrícula de Huexotzinco (Prem 1974): a) folio 602v; b) folio 703r.

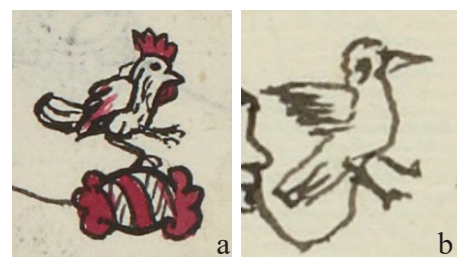

Figura 4: a) Glifo de Castilla en la Matrícula de Huexotzinco (Prem 1974: f. 542r); b) Glifo de Gallo en la Matrícula de Huexotzinco (Prem 1974: f. 687v).

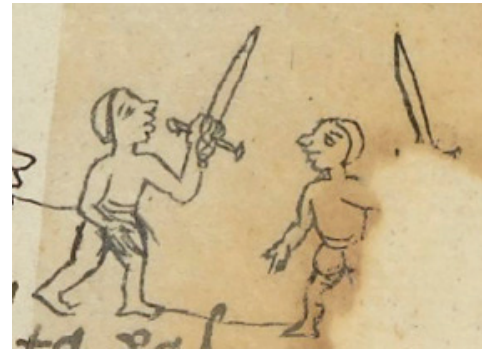

Figura 5: Glifo de Cochillal en la Matrícula de Huexotzinco (Prem 1974: 536r).

aunque en el glifo sólo se plasmó la prenda. En el segundo (Figura 2e), el término tlapal-li «color para pintar, o cosa teñida» (GDN 2012) debería «obligar» a que la camisa estuviera coloreada, pero no lo está, plasmándose de igual modo que en el resto.

CAPA (Figura 3). El glifo de este apellido (Prem 1974: 547) está compuesto por una capa española en los folios 602v y 703v de la Matrícula de Huexotzinco (s/f). Pintadas ambas de gris, se diferencian por su diseño general, incluyendo la forma del cuello, pues son obra de distintos tlacuiloque.

CASTILLA (Figura 4). «diego de Gastila» (Prem 1974: 547) ${ }^{9}$ aparece en el folio 542r de la Matrícula de Huexotzinco ( $\mathrm{s} / \mathrm{f}$ ), componiéndose su glifo mediante el signo fonético te-tl: «piedra» (preposición «de») y el logograma «gallo» o «gallina» para escribir Castilla (Figura 4a). En la imagen destaca el color rojo en la cresta y debajo de la papada del ave, sorprendiendo que también aparezca en la piedra, pues siempre se pinta en marrón. Por otro lado, en el folio $687 \mathrm{v}$ de este mismo documento, se encuentra pintado un indígena que, según su glosa, se llama «juan gallo» pero el diseño del ave (Figura 4b) no permite determinar de qué especie se trata, aunque podemos afirmar que no es ni gallo ni gallina, con lo cual no se trata de un préstamo occidental.

COCHILLAL (Figura 5). En este caso del folio 536r de la Matrícula de Huexotzin$c o(\mathrm{~s} / \mathrm{f})$ encontramos un glifo para «petro. cochillal» compuesto por dos hombres que

sup-infor.com) creado por Marc Thouvenot y las páginas web de Amoxcalli (www.amoxcalli.org.mx) y de la Biblioteca Nacional de Francia (www.gallica.bnf.fr).

9 H.J. Prem (1974: 547) lo recoge en la entrada para «gallo», entre los términos callatl y camatl. 
Figura 6: Glifo de Cristiano en la Matrícula de Huexotzinco (Prem 1974): a) folio 693v; b) folio $720 \mathrm{v}$; c) cabeza de cristiano, folio $536 \mathrm{v}$.
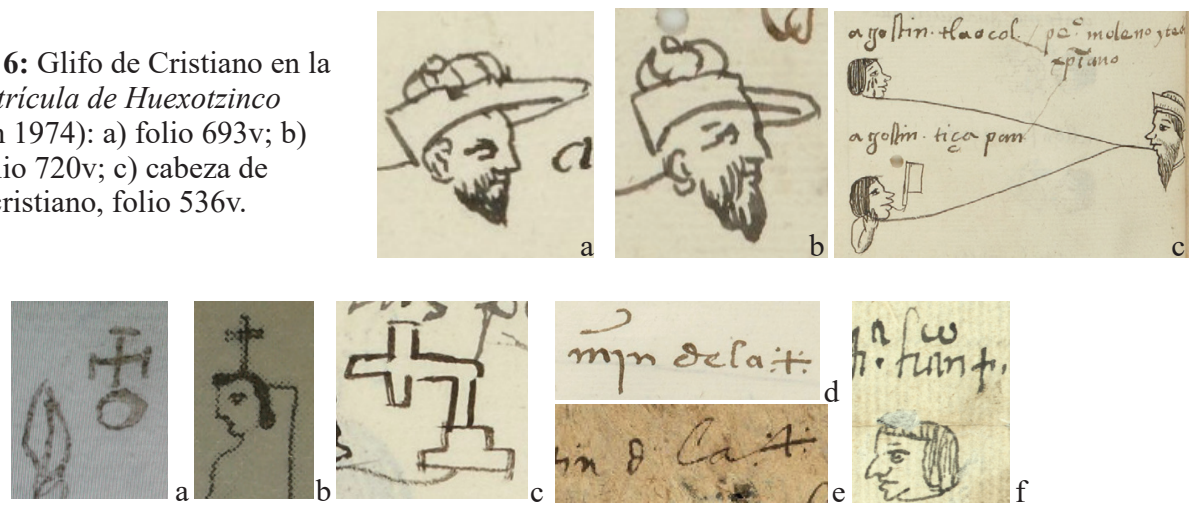

Figura 7: Glifo de Cruz: a) Títulos de la casa que está en el pueblo de Cuauhtitlan (León-Portilla y Brito 2012: 264); b) Lienzo de Miacatlan (Glass y Robertson 1975: fig. 62); c) Matrícula de Huexotzinco (Prem 1974: fol. 664v); d) Matrícula de Huexotzinco (Prem 1974: f. 865r); e) Rôle de Impôts de Tlatengo (s/f); f) Códice de Tecpatepec (Hermann 2001).

pelean con espadas españolas. Debido a su pequeño tamaño y a la mano que tapa el bajo vientre del contendiente que se conserva completo, es imposible determinar si se trata de un indígena (taparrabos), pero en el otro se aprecian los calzones (español). Hanns J. Prem (1974: 557) no determina la procedencia del apellido, incluyéndolo en el apartado ungeklärt- «no aclarado» como (Span.chuchillo?). En nuestra opinión, deriva del náhuatl cuchillohuia- «dar cuchillada» (GDN 2012), que no existiría en esta lengua, creándose tras la adopción del sustantivo castellano cuchillo para el verbo «acuchillar» (Diccionario ... 1992 I: 615).

CRISTIANO (Figura 6). Su logograma se encuentra en los folios 693v y 720v (Figuras $6 \mathrm{a}$ y $6 \mathrm{~b}$ ) de la Matrícula de Huexotzinco (s/f), consistiendo en la cabeza cubierta por una gorra o sombrero de un español que destaca por su barba ${ }^{10}$. Por otra parte, en el folio 536v de este códice se recoge la figuración de «pe[dr]o moleno» (Moreno), representado por un glifo semejante (Figura 6c), pero no actúa de antropónimo sino que expresa la «calidad» de español o cristiano del personaje, que tiene algún tipo de relación con los indígenas a los que está unido con una línea que sale de su boca para desdoblarse en $\operatorname{dos}^{11}$.

CRUZ (Figura 7). El glifo del apellido Cruz (Prem 1974: 553) representa directamente la misma y lo hemos encontrado en 3 códices. Así, en los Títulos de la casa que está en el pueblo de Cuauhtitlan (Glass y Robertson 1975: 120) publicado por M.

10 Hanns J. Prem (1974: 673) no interpreta la glosa, incluyéndola en el apartado ungeklärt- «no aclarado» de la equis como xano. Además sólo relaciona el glifo del folio 693v.

11 En las imágenes de las dos ediciones de la Matrícula de Huexotzinco (Prem 1974 y s/f), el cosido de los cuadernillos no permite abrir en su totalidad el libro encuadernado y sólo se lee ytechp..., impidiendo determinar con claridad qué los une, aunque quizá podría ser itech pohui- «pertenecer a» (GDN 2012), pero los indígenas también se relacionan con la glosa xpiano mediante líneas. Por último, debemos reseñar que en los folios $665 \mathrm{r}$ y $665 \mathrm{v}$ de este mismo códice hay otros dos glifos semejantes al de Cristiano, pero son los nombres del barrio de Teouaca[n], con lo cual serán analizados en otro estudio. 


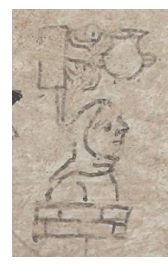

Figura 8: Glifo de San Francisco en la lámina 6 del Códice Mexicanus 23-24 (Menguin 1952).

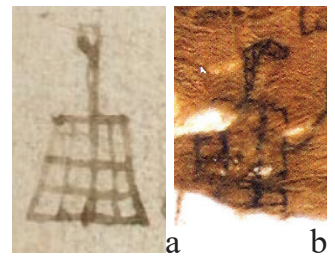

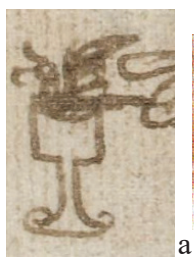
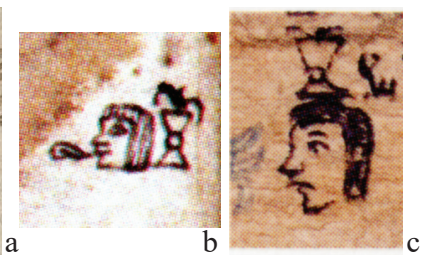

Figura 9: Glifo de Juan: a) Códice de tributos de San Pablo Teocaltitlan (s/f: f. 4v); b) Mapa de Tomatlan (Brotherston 1997: 29); c) Mapa Beinecke (Whittaker 2012: 191).

Figura 10: Glifo de Lorenzo: a) Códice de tributos de San Pablo Teocaltitlan (s/f: 4r); b) Fragmento 5 de Humboldt (Seler 1904).

León-Portilla y B. Brito (2014) ${ }^{12}$ aparecen diversos personajes con glifos de escritura indígena que reflejan tanto sus nombres como apellidos. Para nuestro trabajo nos interesa, en este caso, reseñar a «miguel delacros» (Figura 7a) pues comprobamos que mientras su nombre se escribe con un elemento indígena (mitl-flecha como aproximación fonética para Miguel) el apellido está expresado mediante una cruz sobre el «mundo». Por otro lado, en el Lienzo de Miacatlan aparece el glifo del nombre de uno de los señores representados conformado mediante una cruz, pero no tiene glosa. Aunque no hay imágenes del original (se supone que está en el pueblo), conservamos tres copias del mismo realizadas por Waldeck (Figura 7b), Nebel y León y Gama. Además, en el folio 664v (Figura 7c) de la Matrícula de Huexotzinco $(\mathrm{s} / \mathrm{f})$ tenemos escrito el glifo de «pe[dr]o cruzpoztec» mediante una cruz rota, pues poztec deriva del verbo poztequi- «quebrar o romper» (GDN 2012).

Finalmente, debemos incluir tres casos «especiales» por encontrarse fuera del contexto de glifos que estamos tratando. Así, en el folio 865r de la Matrícula de Huexotzinco (s/f) el glifo no se encuentra en la cabeza del indígena sino en la glosa: «m[art]in de la +» (Figura 7d); en el reverso, sin pinturas, del Rôle des Impôts de Tlatengo (s/f) aparece el nombre de otro «martin $d[\mathrm{e}]$ la $+\gg($ Figura 7e) y en el Códice de Tecpatepec (Hermann 2001) «fran[cis]co +» (Figura 7f), escribiéndose Cruz mediante el logograma + .

FRANCISCO (Figura 8). Pese a estar siempre escrito mediante elementos indígenas, que ofrecen el antropónimo fonéticamente, hay un ejemplo en el cual se introduce uno occidental. Lo encontramos en la lámina 6 del Códice Mexicanus 23-24 (s/f), escribiéndose su nombre de dos formas diferentes en el mismo glifo: una fonética, mediante el uso de pantli- «bandera», cillin- «caracolillo» y comitl- «vasija» (Galarza

12 Conservado en la Biblioteca Nacional de Antropología e Historia de México (Colección Antigua, vol. 2-57), es una copia realizada hacia 1609 del testamento de 1576 de Alonso Begerano (León-Portilla y Brito 2014: 242) que incluye un folio con una pintura relativa a tierras asociadas a indígenas. El copista que la llevó a cabo bocetó los glifos con muy mala calidad, con lo cual en algunos casos es imposible determinar lo que quería reflejar. 


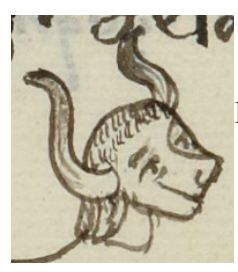

Figura 11: Glifo de

Lucas en la Matrí-

cula de Huexotzin-

co (Prem 1974:

f. $778 \mathrm{v}$ ).
Figura 12: Glifo de San

Miguel en el Códice de tributos de San Pablo

Teocaltitlan (s/f): a) folio $14 \mathrm{r}$; b) folio $14 \mathrm{v}$.

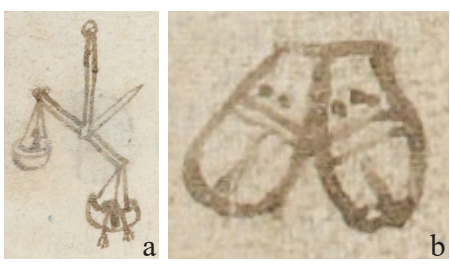

1980: 59); y otra con un único logograma que representa un fraile franciscano cuya lectura consideramos que es Francisco ${ }^{13}$.

$J U A N$ (Figura 9). Para este antropónimo los tlacuiloque tomaron, para conformar su logograma, la iconografía cristiana que representa a San Juan Evangelista mediante el emblema de una copa de la «que se escapa el veneno exorcizado por una señal de la cruz, en forma de dragoncillo de una o varias cabezas» (Réau 2001: 190). Así, mediante el cáliz y el dragón, aparece en el Libro de los tributos de San Pablo Teocaltitlan (s/f) en los folios 4v, 5r, 5v, 6r (3 veces), 6v, 7v, 9r, 11r, 14v (2 ocasiones), 15r, 15v, 16r, 18r, 20v, 22r, 23r y 24v (Figura 9a); en el Códice de Santa Anita Zacatlalmanco (Galarza 1980: 100, lám. 4.2 letra n); en el Mapa de Tomatlan ${ }^{14}$ (Brotherston et.al. 1997: 29) (Figura 9b) y en el Mapa Beinecke (Whittaker 2012: 191) (Figura $9 \mathrm{c})^{15}$. Por otro lado, también lo encontramos plasmado únicamente con la copa o cáliz en el Plano de las casas de Juan Xalbornoz (Galarza 1980: 79, lám. 3.8, nº 1) ${ }^{16}$.

LORENZO (Figura 10). Para escribir este antropónimo los tlacuiloque usaron el logograma de la parrilla en la que el santo fue martirizado (Réau 2001: 258). Así aparece en tres documentos: lámina 86 del Códice Mexicanus 23-24 (Galarza 1980: 79, lám. 3.8, $\mathrm{n}^{\circ}$ 8); folio 4r del Libro de los tributos de San Pablo Teocaltitlan (s/f) (Figura 10a) en el nombre de «juseph lure[n]zo» y en el Fragmento 5 de Humboldt (Seler 1904: entre 188-189) (Figura 10b) ${ }^{17}$ como glifo de «lolenzo te s. fo»-Lorenzo de San Francisco (Seler 1904: 189). En todos ellos se sigue la iconografía cristiana al incluir el asa de la parrilla.

LUCAS (Figura 11). Sólo hemos encontrado un glifo con el nombre Marcos de San Lucas en el folio 778v (Figura 11a) de la Matrícula de Huexotzinco (s/f), escribiéndose mediante el buey, símbolo de San Lucas Evangelista en la iconografía cristiana (Réau 2001: 264). Por otro lado, en el folio 744v de este documento el glosador denomina a uno de los indígenas como «lucas evagelisda», pero el glifo se compone

\footnotetext{
13 Resulta muy curioso que, en este ejemplo doble de escritura del nombre en el mismo glifo mediante un logograma y signos fonéticos, Joaquín Galarza (1980: 54 y 59) indique que el pintor «añadió a la representación iconográfica [cursiva nuestra; véase Batalla 2008: 58-59] del santo los signos tradicionales que expresan fonéticamente San Francisco».

14 De todos los códices citados en nuestro trabajo, este es el único que no aparece recogido en la página web de wiki filología (véase nota 2 ).

15 Aunque este investigador interpreta el glifo pintado como Juan con una interrogación, analizándolo con detenimiento (Mapa Beinecke, s/f) se observan la cabeza y la cola del dragón.

16 En los Títulos de la casa que está en el pueblo de Cuauhtitlan (León-Portilla y Brito 2014: 264) está pintado otro glifo de Juan, pero su diseño es imposible de determinar debido a su mala calidad, aunque pensamos que puede tratarse del logograma xihuitl- «turquesa, precioso», pues fonéticamente se asemeja a la pronunciación de Juan, pero no sería un préstamo.

17 Joaquín Galarza (1980) no lo recoge en su estudio pese a utilizar este documento para incluir el glifo de María que contiene.
} 

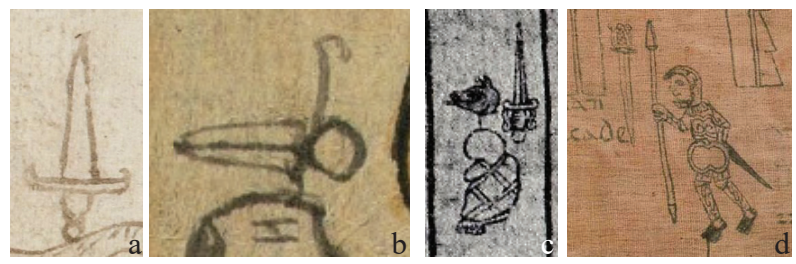

Figura 13: Glifo de Pablo; a) Códice de tributos de San Pablo Teocaltitlan (s/f: f. 22v); b) Rôle de Impôts de Tlatengo (s/f); c) Códice en Cruz (Dibble 1981); d) Lienzo de don Juan Chichimeca Tecuhtli (Caso 1965).

de un ave (Figura 11b) y no hemos hallado relación entre ningún pájaro concreto y San Lucas (Réau 2001: 264-265), salvo que el buey puede aparecer en la iconografía cristiana con alas.

MIGUEL (Figura 12). El antropónimo Miguel normalmente aparece escrito por elementos indígenas con diseños más o menos aculturados: flecha, ala, bulto mortuorio, etc. (véase Galarza 1980: $55-56$ y 60 ) ${ }^{18}$, pero hay un glifo muy interesante relativo al arcángel San Miguel que se compone por un logograma representativo de uno de sus símbolos característicos: la balanza que utilizará en el Juicio Final para determinar las buenas y malas acciones de los hombres (Ferrando 1950: 200-201 ${ }^{19}$ ). De este modo, en el folio 20r del Libro de los tributos de San Pablo Teocaltitlan (s/f) encontramos a una indígena llamada Ana de San Miguel (Figura 12a) cuyo glifo es un peso que contiene en cada platillo dos figuras humanas: en el derecho, caída sobre el plato y con los brazos sobresaliendo del mismo y en el izquierdo, de pie en el recipiente. Debemos reseñar, finalmente, que este documento contiene otro glifo totalmente diferente para Miguel en sus folios 8r, 9v, 14r, 14v, 15r, 15v y 16v (Figura $12 b)$ no encontrado en otros códices, pero de momento no hemos conseguido determinar su significado y su relación con este nombre.

$P A B L O$ (Figura 13). La espada de su martirio es el símbolo iconográfico que lo caracteriza (Réau 2002: 10-11), mismo logograma que utilizaron los pintores indígenas para escribir este nombre en los códices Alfareros de Cuauhtitlan, Mexicanus 23-24 y Proceso de Cuauhtitlan (Galarza 1980: 78, lám. 3.7, nº 3, 4, 7, 9). Además, lo encontramos en los folios 4v y 22v (Figura 13a) del Libro de los tributos de San Pablo Teocaltitlan (s/f) y en el Rôle des Impôts de Tlatengo (s/f) otras dos veces (Figura 13b).

Por otro lado, el Códice en Cruz (Dibble 1981) recoge en la columna correspondiente al año 8-conejo (1530) un bulto mortuorio (Figura 13c) con su glifo correspondiente unido por una línea a su cabeza y al lado la espada de San Pablo, con lo cual podría reflejar su nombre cristiano. No obstante, Ch. E. Dibble (1942: 124 y 125) señala que la espada en este caso «debe indicar la forma en que murió». Consideramos que su apreciación viene dada por varios motivos: el arma no está unida por la línea a la cabeza del gobernante, su glifo ya se había pintado en la columna de 1525 sin ella y en 1530 no gobernaba en Tenochtitlan ningún Pablo, sino Andrés de Tapia

18 En la Matrícula de Huexotzinco (s/f), hemos hallado otros dos glifos del antropónimo San Miguel: uno está compuesto por un pájaro de color verde (posiblemente un colibrí por su largo pico) con las alas totalmente desplegadas (folio 708v), y el otro por la cabeza de un conejo y tres huellas de pie (folio 732r); pero en ningún caso se trata de elementos occidentales.

19 J. Ferrando (1950: 201) incluye una imagen de un mural del siglo XIII en el que se ve el hombre «malo»-demonio en el platillo de la izquierda y el «bueno»-orador en el derecho. 
Figura 14: Glifo de Pastor en la Matrícula de Huexotzinco (Prem 1974: f. 614v).
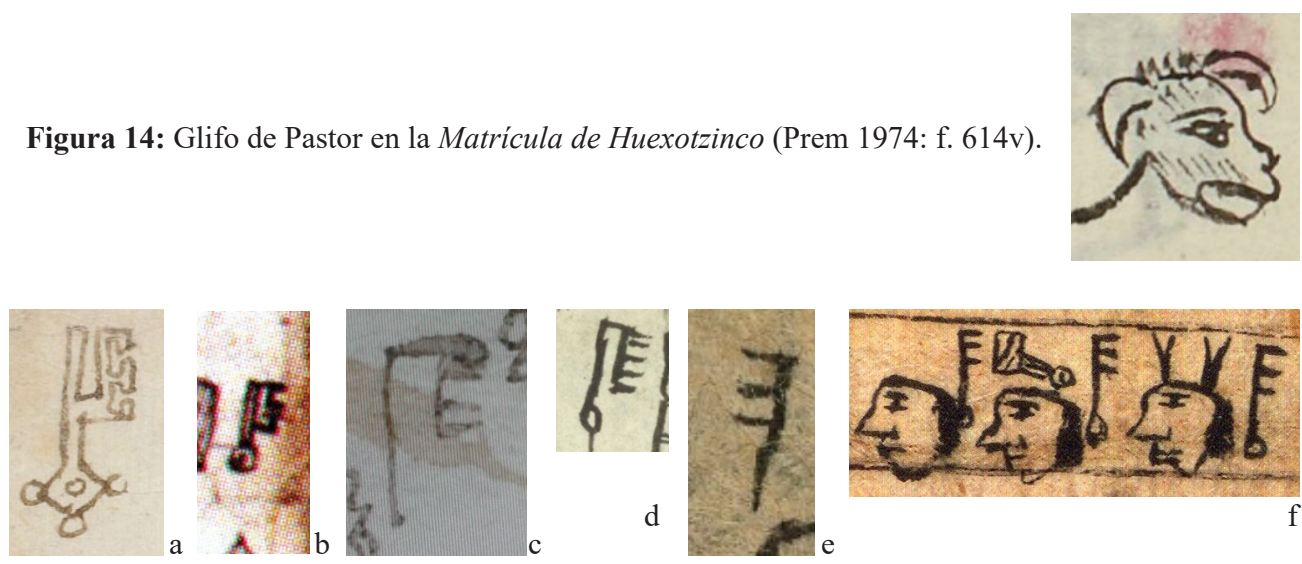

Figura 15: Glifo de Pedro: a) Códice de tributos de San Pablo Teocaltitlan (s/f: f. 8r); b) Mapa de Tomatlan (Brotherston 1997: 29); c) Títulos de la casa que está en el pueblo de Cuauhtitlan (LeónPortilla y Brito 2012: 264); d) Códice Valeriano (Mateos 1949); e) Rôle de Impôts de Tlatengo (s/f);

f) Fragmento Humboldt 14 (Seler 1904).

Motelchiuhtzin. De igual manera, en el Códice de don Juan Chichimeca Tecuhtli o Lienzo Vischer II (Caso 1965) el tlacuilo pintó al lado izquierdo de «don Juan» la espada de Pablo (Figura 13d), pero no tiene ningún nexo de unión con el personaje. Por ello, nos limitamos a indicar la presencia del logograma en estos dos documentos sin poder afirmar cómo debe ser interpretado.

PASTOR (Figura 14). El nombre de «p[edr]o pastol» está escrito en el folio $614 \mathrm{v}$ de la Matrícula de Huexotzinco (s/f), recurriendo el tlacuilo a una cabeza de carnero ${ }^{20}$ para expresar el apellido Pastor del indígena (Prem 1974: 598).

PEDRO (Figura 15). Aparece escrito con el logograma de la llave de las puertas del cielo como símbolo cristiano (Réau 2002: 50-51) en gran número de códices, tanto como nombre del santo propiamente dicho, como apelativo de barrio y como antropónimo de persona. Además tiene un problema añadido que, en ocasiones, impide determinar con claridad a qué se refiere el logograma, pues el título u oficio de mayordomo también se refleja a nivel escriturario e iconográfico mediante una llave y en algunos casos concretos resulta complicado determinar si se trata de un antropónimo o de un oficio.

Joaquín Galarza (1980: láms. 3.3, 3.7, 3.11, 4.2 y 6.2) recoge el logograma de la llave en diversos documentos como los códices Alfareros de Cuauhtitlan, Proceso de Cuauhtitlan y Santa Anita Zacatlalmanco, pero este glifo se encuentra pintado en otros. De este modo, en el Libro de los tributos de San Pablo Teocaltitlan (s/f) aparece en los folios 7v, 8r, 13r, 13v, 15r, 18r, 20v, 21v y 22v (Figura 15a), en el Mapa de

20 En el Códice Sierra (s/f) aparece en 8 ocasiones la figuración del carnero con la cabeza diseñada de igual modo. Descrito en todas ellas bajo el término ichcatl- «carnero» (GDN 2012), destaca la lámina 33 (folio 17r) de este documento por incluir en el texto explicativo de la imagen del animal los términos ichcapixqui- «ganadero o pastor» (GDN 2012) y carneros oquichtli; es decir, carneros macho-oquichtli (GDN 2012), resultando además que es la única representación del animal en el códice que presenta los testículos dibujados. 

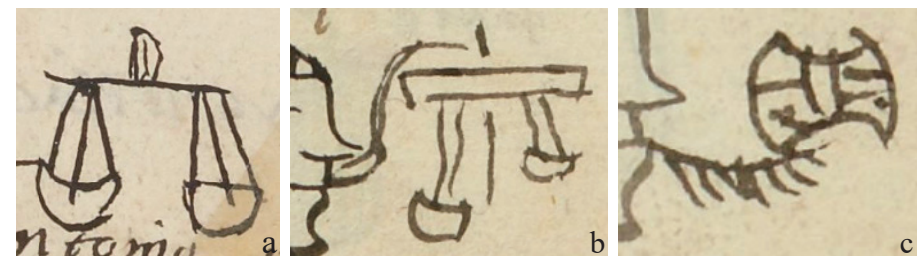

Figura 16: a) Pexoita (Prem 1974: f. 490r); b) Quapeso (Prem 1974: f. 579v); c) Yaotentzo (Prem 1970: f. 579v).

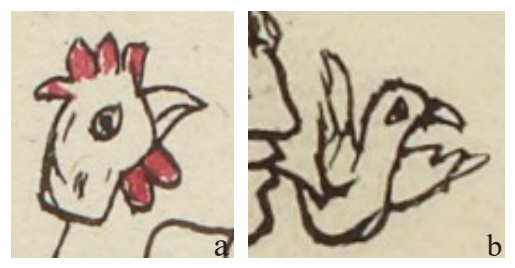

Figura 17: Glifo de Pío en la Matrícula de Huexotzinco (Prem 1974): a) folio 901r; b) folio 744 r.

Tomatlán (Brotherston et.al. 1997: lámina 1) (Figura 15b) y, con un diseño muy deficiente, en los Títulos de la casa que está en el pueblo de Cuauhtitlan (León-Portilla y B. Brito 2014: 264) (Figura 15c).

Finalmente, el logograma de la llave también está presente en diversos glifos de los códices Valeriano (Mateos 1949) (Figura 15d), Rôle des Impôts de Tlatengo (Figura 15e) y Fragmento Humboldt 14 (Figura 15f). En el primero de ellos pensamos que el glifo puede hacer referencia al oficio de mayordomo, mientras que en el segundo y tercero (posiblemente dos fragmentos del mismo códice), los que sólo tienen el logograma de la llave, podrían estar reflejando este cargo, pero lo mismo ocurre con el nombre de Pablo (véase Figura 13b), con lo cual creemos que, en este caso, todos reflejan el antropónimo Pedro, incluidos los que no contienen el glifo con el «apellido» náhuatl.

PESO (Figura 16). La glosa que lee el antropónimo no presenta al mismo individualizado, sino que en los dos casos encontrados está unido a un término náhuatl. Ambos se hallan en la Matrícula de Huexotzinco (s/f): «antonio pexoyta» (folio 490r) y «jua[n] quapeso» (folio 579v). Para Hanns J. Prem (1974: 599 y 605) derivan del verbo náhuatl pexouia- «pesar», es decir, un verbo tomado de un préstamo castellano («peso», adaptado fonéticamente con la forma pexo) y un sufijo verbalizador náhuatl -huia (véase Lockhart 1999: 378-468), que ya tenía otros términos propios como tlamachihua (GDN 2012).

El glifo del primero de ellos, pexoyta (Figura 16a), presenta el logograma de una balanza o peso con su fiel, pero no se halla ningún elemento que ofrezca la lectura de la palabra yta, que podría referirse, por ejemplo, al verbo itta- «ver o mirar» (GDN 2012) o simplemente a una «degeneración» directa de pexouia en pexoyta. El segundo, quapeso (Figura 16b), resulta más complicado, pues el glifo contiene otro elemento. Analizando la totalidad del folio $579 \mathrm{v}$ donde está pintado, se observa que el tlacuilo une los glifos a la boca del indígena con una simple línea, salvo en el glifo de gaspal yaotentzo (Figura 16c), donde plasma «pelos» sobre la misma para escribir tentzo-tli: «barua, los pelos» (GDN 2012); y en quapeso, donde también conforma una unión que no es la normal, pues tiene un trazo doble que lleva a otra en sentido vertical y partida en dos. La sílaba qua o cua puede ser el inicio de múltiples térmi- 


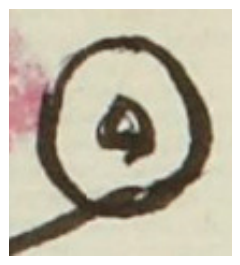

Figura 18: Glifo de Tomín en la Matrícula de Huexotzinco (Prem 1974: f. 569v).
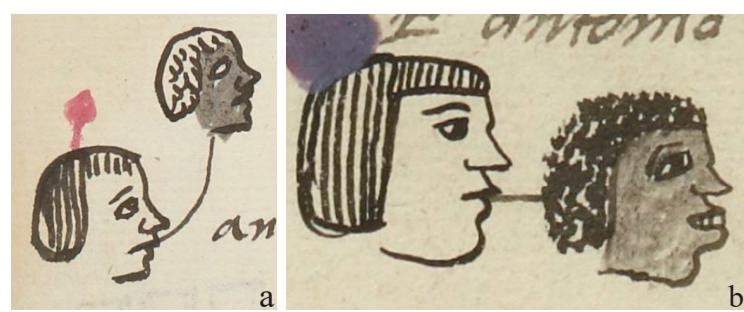

Figura 19: Glifo de Copan en la Matrícula de Huexotzinco (Prem 1974): a) folio 484r; b) folio 711r.

nos (véase Prem 1974: 602-604 y GDN 2012), resultando difícil entender qué quiso escribir el tlacuilo.

PIO (Figura 17). Los antropónimos pio y piotli se encuentran, respectivamente, en los folios 901r y 744r de la Matrícula de Huexotzinco (s/f) y para Hanns J. Prem (1974: 600) derivan del término español «Pio = Spanisch: Hühnerpiepen» (pitido del pollo), es decir, de una palabra castellana «adoptada» por la lengua náhuatl. En este caso se trataría de la onomatopeya española de la «voz que forma el pollo de cualquier ave» (Diccionario ... 1992 II: 1608) tomada prestada por el náhuat ${ }^{21}$ para definir al pollo (véase GDN 2012). Ahora bien, mientras que en el caso de «al[ons]o pio» el logograma es totalmente occidental (Figura 17a), pues refleja la cabeza de una gallina o gallo, para «luis piotli» (Figura 17b) el tlacuilo pintó un ave genérica que puede ser leída de cualquier manera.

TOMÍN (Figura 18). El nombre «baltasal tomin» aparece en el folio 569v de la Matrícula de Huexotzinco (s/f) escrito mediante el logograma de la moneda española denominada tomín (Prem 1974: 636). En este caso, al contener un punto dentro del círculo, el tlacuilo realmente pintó 1 tomín ${ }^{22}$ como genérico para el antropónimo.

\section{Antropónimos no descifrados}

Como ya hemos señalado, en este apartado hemos incluido aquellos ejemplos en los que no hemos conseguido interpretar con claridad tanto el significado del glifo o la glosa que lo acompaña como hacer coincidir ambas y, finalmente, la imposibilidad de leer el primero por la ausencia de glosa explicativa.

COPA[N] (Figura 19). En los folios 484r y 711r de la Matrícula de Huexotzinco $(\mathrm{s} / \mathrm{f})$ encontramos dos indígenas llamados antonio copa[n], escribiéndose Copan mediante el mismo logograma, aunque se trata de tlacuiloque diferentes.

21 Nos resulta imposible pensar que en náhuatl tuvieran la misma onomatopeya para el sonido del pollo de cualquier ave, con lo cual creemos también que está tomada del español.

22 Los tomines se encuentran representados en muchos códices expresando de cuántos se trata mediante varios «puntos» en el interior de la circunferencia, indicando medio tomín (un semicírculo), dos, tres, etc. (véase, por ejemplo, el Libro de los tributos de San Pablo Teocaltitlan, s/f). También es muy común escribir el número arábigo en el círculo, como ocurre en el antropónimo náhuatl de pablo teocuitlatequitl (véase Batalla, en prensa), escrito en el folio 559v de la Matrícula de Huexotzinco (s/f) mediante el logograma de la moneda con un 4 en su interior, con lo que realmente lo pintado son 4 tomines. 

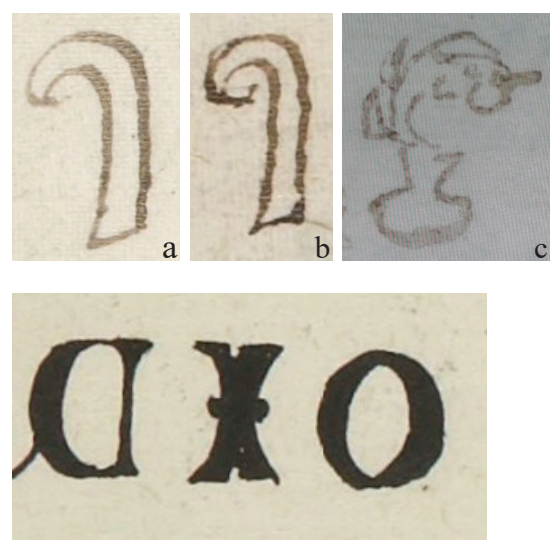

Figura 20: Glifo de Gregorio: a) Códice de tributos de San Pablo Teocaltitlan (s/f: f. 12r); b) Códice de tributos de San Pablo Teocaltitlan (s/f: f. 17v); c) Títulos de la casa que está en el pueblo de Cuauhtitlan (León-Portilla y Brito 2012: 264).

Figura 21: Glifo de Penton en la Matrícula de Huexotzinco (Prem 1974: f. 514r).

Así, en el primer caso (Figura 19a) vemos como glifo la cabeza de un hombre de color caracterizado como tal por su cara negra y el pelo corto y rizado. Comparando estos detalles pictóricos con el resto de cabezas de indígenas que pinta este tlacuilo en el mismo folio resulta muy claro que se trata de un hombre negro. En el segundo ejemplo (Figura 19b), aún resalta mucho más la diferencia, pues el pintor añade los labios abultados y una gran dentadura. Por tanto, podemos afirmar que ambos logogramas son préstamos de la nueva cultura. Ahora bien, el problema radica en el término escrito en ambas glosas: copa[n], pues no hemos encontrado ninguna palabra castellana ni náhuatl que pueda referirse con claridad a lo representado ${ }^{23}$.

GREGORIO (Figura 20). Su antropónimo aparece en los folios 12r y 17v (Figuras 20a y 20b) del Libro de los tributos de San Pablo Teocaltitlan (s/f). En ambos casos el logograma consiste en un objeto semejante a un báculo, pero ningún "Gregorio» del santoral lo porta como definitorio en la iconografía cristina (Réau 2001: 44-56). Además, en los Títulos de la casa que está en el pueblo de Cuauhtitlan (León-Portilla y Brito 2014: 264) (Figura 20c) encontramos otro glifo compuesto por una olla de la que sale ¿humo? que se curva hacia la derecha. Por ello, es posible que su lectura sea la de un término náhuatl que fonéticamente sea similar a Gregorio, pero los nombres para curvo, torcido, doblado, etc., nos remiten a coloa, colochoa, coltic, etc. (GDN 2012), con lo cual tampoco parece muy probable; aunque H.J. Prem (1970: 164, fig. 4e) lo interpreta como «a bended stick, choltic» ${ }^{24}$.

PENTON (Figura 21). La glosa con el nombre de «pe[dr]o penton» aparece escrita en el folio 514r de la Matrícula de Huexotzinco (s/f) acompañada por un glifo compuesto por tres grandes letras mayúsculas: una $\mathrm{D}$ invertida o $\mathrm{C}$ cerrada, una $\mathrm{X}$ o I y una O. Hanns J. Prem (1974: 598) lo recoge como «pendon = Spanisch: Banner»

23 Hanns J. Prem (1974: 557) incluye el antropónimo en el apartado ungeklärt- «no aclarado» de la letra c. Por nuestra parte, sólo hemos encontrado las palabras nahuas tlacopo y tlacopotli (GDN 2012) para esclavo o siervo pero, por mucho que el glosador «corrompiera» las mismas, no nos acaba de convencer que sean estos términos, si bien su traducción al castellano encaja perfectamente con el logograma escrito por los tlacuiloque. Por ello, este nombre también lo incluiremos en nuestro trabajo sobre antropónimos nahuas (Batalla, en prensa).

24 Suponemos que se trata de un error de impresión y que la palabra es coltic- «cosa torcida o tuerta» (GDN 2012). 
Figura 22: Glifo de Santiago: a) Matrícula de Huexotzinco (Prem 1974: f. 720v);

b) Códice Telleriano-Remensis (s/f: f. 44r);

c) Títulos de la casa que está en el pueblo de Cuauhtitlan (León-Portilla y Brito 2012: 264).

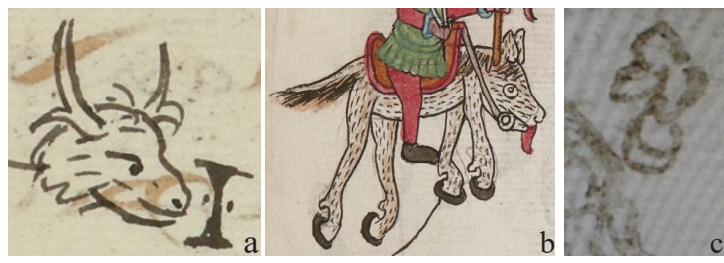

Figura 23: Glifo de Tomás: a) Mapa Beinecke (Whittaker 2012: 188); b) Títulos de la casa que está en el pueblo de Cuauhtitlan (León-Portilla y Brito 2012: 264).
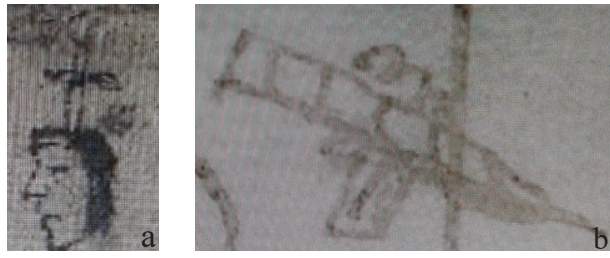

(bandera, estandarte), pero no hemos encontrado el posible significado del logograma escrito. Únicamente podemos señalar que la grafía de las letras es muy semejante a la que aparece en los folios del documento donde se recoge el nombre de la localidad a la que corresponde el censo de personas que se desarrolla a continuación.

SANTIAGO (Figura 22). El glifo de «lorenço De S[an]tiago» escrito en el folio $720 \mathrm{v}$ de la Matrícula de Huexotzinco (s/f) resulta muy complejo (Figura 22a), pues se compone del logograma mazatl- «venado» y el complemento fonético i, cuya grafía es muy similar a la presente en otros folios del códice cuando se escriben los nombres de las localidades en mayúsculas. Lo complicado es relacionar el logograma con el nombre de Santiago. De hecho, únicamente se nos ocurre una respuesta un tanto «rebuscada»: Santiago Matamoros ecuestre (Réau 2002: 177), cuya característica iconográfica es el caballo. Así, por un lado, debemos recordar que según James Lockhart (1999), en lo que él denomina Etapa 1 ( $c a$. 1519-1550) de préstamos lingüísticos (Lockhart 1999: 378), los hablantes de náhuatl utilizaron el término «mazatl» para denominar al caballo (Lockhart 1999: 390-392), si bien en la Etapa 2 (ca. 1550-mitad siglo XVII) ya adaptaron el préstamo «cahuallo» (Lockhart 1999: 421-422). Por otra parte, en su análisis del folio 44r del Códice Telleriano-Remensis, E. Quiñones (1995: 233-234) señala que el tlacuilo que pintó el caballo representado en el mismo lo hizo como un venado: «The depiction of the horse as a deerlike animal» (Figura $22 b$ ), pues basa su anatomía en otro animal familiar y, según su opinión, aunque al encontrarse ya en la segunda mitad del siglo XVI lo conocía sobradamente, lo hizo a propósito.

Por ello, aunque la Matricula de Huextzinco se data en 1560, podríamos suponer que, en este caso concreto, el tlacuilo de estos folios utiliza mazatl como logograma de cahuallo, incluyendo un término totalmente occidental, una $i$ mayúscula, como complemento fonético que determina cómo debe ser leído el logograma. Esta hipótesis podría ser válida siempre y cuando no tengamos en cuenta que el glosador se pudo equivocar cuando escribió el nombre e incluso inventárselo. Además, en todos los casos en los que aparece este logograma en la Matrícula de Huexotzinco, personalmente hemos contabilizado al menos 115 veces, siempre se lee como venado.

Finalmente, debemos indicar que en los Títulos de la casa que está en el pueblo de Cuauhtitlan (León-Portilla y Brito 2014: 264) hay un alonso de s.[an]tigo pero, debi- 


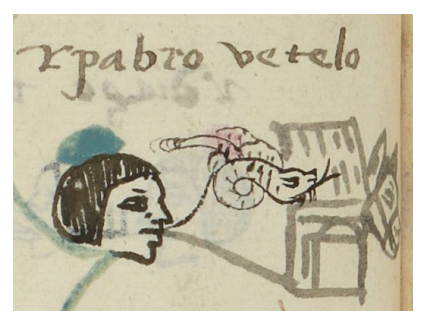

Figura 24: Glifo de Ventero en la Matrícula de Huexotzinco (Prem 1974: fol. 614v).

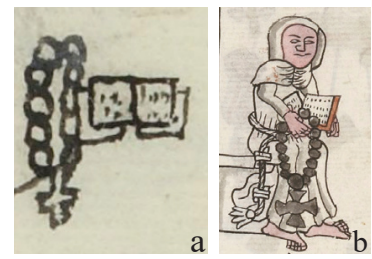

Figura 25: a) Glifo compuesto por un rosario y un libro en la Matrícula de Huexotzinco (Prem 1974: f. 861v); b) Códice Telleriano-Remensis (s/f: f. 46r).

do a lo deficiente del diseño (Figura 22c), sólo es reconocible el glifo de Alonso: $a-t l$ (agua) + tototl (pájaro), que también era utilizado comúnmente para escribir Antonio.

TOMÁS (Figura 23). Entre los glifos de antropónimo escritos en el Mapa Beinecke (s/f), cabe destacar uno en el que el logograma es una espada clavada en la cabeza de un indígena (Figura 23a). Gordon Whittaker (2012: 188, $\mathrm{n}^{\circ} 112$ ) considera que puede tratarse de Pablo (véase Figura 13), pero en todos estos casos el arma se encuentra separada del individuo al que da nombre. Por ello, en nuestra opinión, podría tratarse de Santo Tomás Becket de Canterbury, pues alcanzó gran devoción en España como Santo Tomás Cantuariense, fue «uno de escasos santos ingleses que llegó a convertirse en un santo universal» y como mártir se le representa con «una espada hundida en el cráneo» (Réau 2002: 277-278). Por ello, consideramos que se trata de Tomás. Por último, en los Títulos de la casa que está en el pueblo de Cuauhtitlan (LeónPortilla y Brito 2014: 264), encontramos otro thomas (Figura 23b) cuyo antropónimo está escrito mediante distintos elementos entre los que, pese a su mala calidad pictórica, creemos reconocer al menos una lanza. Por ello, pensamos que podría hacer referencia a Tomás Apóstol, pues es el arma de su martirio (Réau 2002: 271), pero de ser así no lo podríamos calificar como préstamo occidental.

VENTERO (Figura 24). Aunque todo parece indicar que realmente se corresponde con un oficio, debemos reseñar el glifo que acompaña a «pabro uetelo» en el folio $614 \mathrm{v}$ de la Matrícula de Huextzinco (s/f), pues ese es el nombre escrito en su glosa ${ }^{25}$ y no el que indica el otro glifo que le acompaña: mixcoatl. El logograma destaca por la cabeza de un asno o caballo y una casa, con lo cual hemos considerado oportuno incluirlo en este trabajo.

Sin glosa (Figura 25). En el folio 861v de la Matrícula de Huexotzinco (s/f) encontramos el glifo de un indígena llamado «pedro» (Figura 25a), pero el glosador no escribió su «apellido». Por ello, no podemos interpretar su lectura y si esta sería náhuatl o castellano, pues el rosario y el libro son elementos comunes a muchos santos (Ferrando 1950: 280 y 283; Réau 2002: 537 y 551) y, por ejemplo, en el folio 46r del

25 Hanns J. Prem (1974: 663) lo recoge como «no aclarado» en la letra u. 
Códice Telleriano-Remensis se encuentra pintado un fraile con ambos objetos en sus manos (Figura 25b).

\section{Conclusiones}

En este primer trabajo sobre elementos occidentales en los glifos de escritura indígena de los códices coloniales nos hemos centrado exclusivamente en los referidos a los antropónimos castellanos. Somos conscientes de que falta mucho por hacer, pero de momento el resultado del análisis demuestra que los tlacuiloque indígenas no dudaron en tomar prestados de la cultura europea todo tipo de iconos que les permitieran facilitar la escritura de ciertos términos, para ofrecer su «lectura» tanto a españoles como a indígenas.

De este modo, la aculturación se produjo también en la escritura logosilábica indígena, pues no sólo recurrió a la escritura fonética de estos «nuevos» nombres mediante elementos tradicionales, sino que sus «escribanos» no dudaron en incluir lo que era totalmente desconocido para ellos.

Por último, debemos indicar que somos conscientes de que este análisis no puede considerarse cerrado, pues aparecerán nuevos documentos, o se editaran por cualquier medio a lo largo del tiempo, pero del mismo modo que nosotros hemos ido un poco más lejos que Joaquín Galarza, algún investigador superará el número de antropónimos que nosotros hemos relacionado.

Agradecimientos: El estudio que ha dado lugar a estos resultados ha recibido financiación del Consejo Europeo de Investigación en virtud del Séptimo Programa Marco de la Comunidad Europea [7 $\left.{ }^{\circ} \mathrm{PM} / 2007-2013\right]$ tras el acuerdo de subvención del CEI ${ }^{\circ}$ 312795. Este proyecto de investigación ha sido dirigido por la Dra. Justyna Olko de la Universidad de Varsovia.

\section{Referencias bibliográficas}

Batalla Rosado, Juan José

2008 «Los códices mesoamericanos: métodos de estudio». Itinerarios. Revista de estudios lingüísticos, literarios, históricos y antropológicos 8: 43-66.

e.p. «Análisis de elementos gráficos de contenido occidental en los glifos de los códices coloniales del centro de México: el caso de los antropónimos nahuas», en Códices del centro de México. Análisis comparativos y estudios individuales. Volumen II, Juan José Batalla y José Luis de Rojas, eds. Varsovia: Facultad de Filologías Modernas.

Brotherston, Gordon, Galen BroKaw, Aaron Dziubisnky, Millie Gimmel y Mark Morris 1997 Footprints through Time. Mexican Pictorial Manuscripts at the Lilly Library. Bloomington: Indiana University.

CAso, Alfonso

1965 «El Lienzo Vischer II». Homenaje a Juan Comas en su 65 aniversario 1: pp. 193200. México: Editorial Libros de México. 
Códice Mexicanus

s/f Original. Documento electrónico, http://gallica.bnf.fr/ark:/12148/btv1b55005834 g.r=codex \%20mexicanus, con acceso el 15/10/2014.

Códice Sierra

s/f Original. Documento electrónico, http://bdmx.mx/detalle_documento/?id_cod= 26, con acceso el 15/10/2014.

Códice Telleriano-Remensis

s/f Original. Documento electrónico, http://gallica.bnf.fr/ark:/12148/btv1b8458267s/ f46.image.r $=$ codex\%20telleriano-remensis, con acceso el 15/10/2014.

DibBle, Charles E.

1942 Códice en Cruz. México.

1981 Codex en Cruz. Salt Lake City: University of Utah Press.

Diccionario de la Lengua Española

1992 Madrid: Real Academia Española.

FERRANDo RoIG, Juan

1950 Iconografía de los Santos. Barcelona: Ediciones Omega S.A.

GaLARZA, Joaquín

1962 «Le Codex Santa Anita Zacatlalmanco». Journal de la Société des Américanistes 51: 7-33.

1980 Estudios de escritura indígena tradicional Azteca-Nahuatl. México: Archivo General de la Nación.

GLAss, John B. y Donald RoberTson

1975 «A Census of Native Middle American Pictorial Manuscript». Handbook of Middle American Indians. Vols. 14 and 15: Guide to Ethnohistorical Sources, Parts Three and Four, Howard F. Cline, ed., pp. 81-252. Austin: University of Texas Press.

Gran Diccionario Nahuatl (GDN)

2012 México: Universidad Nacional Autónoma de México. Documento electrónico, http://www.gdn.unam.mx, con acceso el 15/10/2014.

FERRANDo RoIG, Juan

1950 Iconografía de los Santos. Barcelona: Ediciones Omega S.A.

Hermann Lejarazu, Manuel

2001 «Códices tributarios de Mizquiahuala», en Códices del Estado de Hidalgo, Laura E. Sotelo, Víctor M. Ballesteros y Evaristo Luvián, coords., pp. 88-99. México: Universidad Autónoma del Estado de Hidalgo.

León-Portilla, Miguel y Baltazar Brito Guadarrama

2014 «El testamento de Alonso Begerano en náhuatl». Estudios de Cultura Náhuatl 48: 235-265.

Libro de los Tributos de San Pablo Teocaltitlan

s/f Original. Documento electrónico, http://gallica.bnf.fr/ark:/12148/btv1b8455947h. $\mathrm{r}=$ Libro $\% 20 \mathrm{de} \% 20$ tributos $\% 20 \mathrm{de} \% 20 \mathrm{San} \% 20 \mathrm{Pablo} \% 20$ Teocaltitlan, con acceso el $15 / 10 / 2014$.

LOCKHART, James

1999 Los nahuas después de la Conquista. Historia social y cultural de la población indígena del México Central, siglos XVI-XVIII. México: FCE. 
Mapa Beinecke

s/f Original. Documento electrónico, http://beinecke.library.yale.edu/collections/ highlights/codex-reese, con acceso el 15/10/2014.

Mateos Higuera, Salvador

1949 «Códice Valeriano». El México Antiguo 7: 315-321.

Matrícula de Huexotzinco

s/f Original. Documento electrónico, http://gallica.bnf.fr/ark:/12148/btv1b8470185f. $\mathrm{r}=$ huexotzinco, con acceso el 15/10/2014.

Nahuatl Dictionary

s/f Documento electrónico, http://whp.uoregon.edu/dictionaries/nahuatl/, con acceso el 15/10/2014.

PREM, Hanns J.

1970 «Aztec Hieroglyphic Writing System - Possibilities and Limits», en Verhandlungen des XXXVIII Internationalen Amerikanistenkongresses 2: 159-165. Munich: Klaus Renner.

1974 Matricula de Huexotzinco (Ms. Mex. 387 der Bibliothèque Nationale Paris). Graz: Akademische Druck und Verlagsanstalt.

QuiÑONEs KeBER, Eloise

1995 Codex Telleriano-Remensis. Ritual, Divination, and History in a Pictorial Aztec Manuscript. Austin: University of Texas Press.

RÉAU, Louis

2000 Iconografía del arte cristiano. Iconografía de los santos. De la A a la F. Barcelona: Ediciones del Serbal.

2001 Iconografia del arte cristiano. Iconografía de los santos. De la G a la O. Barcelona: Ediciones del Serbal.

2002 Iconografía del arte cristiano. Iconografía de los santos. De la P a la Z-Repertorios. Barcelona: Ediciones del Serbal.

Rôle des Impôts de Tlatengo

s/f Original. Documento electrónico, http://gallica.bnf.fr/ark:/12148/btv1b52503868g/ f1.item.r $=\mathrm{R} \% \mathrm{C} 3 \% \mathrm{~B} 4 \mathrm{e} \% 20 \mathrm{des} \% 20 \mathrm{imp} \% \mathrm{C} 3 \% \mathrm{~B} 4 \mathrm{ts} \% 20 \mathrm{de} \% 20$ Tlatengo, con acceso el 15/10/2014.

SELER, Eduard

1904 «Alexander von Humboldt's picture manuscripts in the Royal Library at Berlin», en Mexican and Central, American Antiquities, Calendar Systems, and History, pp. 123-230. Washington: Goverment Printing Office.

WHITTAKER, Gordon

2012 «Individuals Named Hieroglyphycally on the Plots of the Beinecke Map», en Painting a Map of Sixteenth-Century Mexico City. Land, Writing, and Native Rule, Mary E, Miller y Barbara E. Mundy, eds., pp. 181-191. New Haven: Yale University Press. 